\title{
From Denmark to Delhi: the multisectoral challenge of regulating trans fats in India
}

\author{
Shauna M Downs ${ }^{1, *}$, Anne Marie Thow ${ }^{1}$, Suparna Ghosh-Jerath ${ }^{2}$, Justin McNab ${ }^{1}$, \\ K Srinath Reddy ${ }^{3}$ and Stephen R Leeder ${ }^{1}$ \\ 'Menzies Centre for Health Policy, School of Public Health, Faculty of Medicine, University of Sydney, Victor \\ Coppleson Building (D02), University of Sydney, Sydney, NSW 2006, Australia: ${ }^{2}$ Indian Institute of Public \\ Health (Delhi), Public Health Foundation of India, Gurgaon, India: ${ }^{3}$ Public Health Foundation of India, \\ New Delhi, India
}

Submitted 18 April 2012: Final revision received 15 August 2012: Accepted 6 September 2012: First published online 20 November 2012

\begin{abstract}
Objective: India has proposed legislating an upper limit of trans fat in partially hydrogenated vegetable oils and mandating trans fat labelling in an effort to reduce intakes. The objective of the present study was to examine the complexities of regulating trans fat in India by examining the policy processes involved and the perceived implementation challenges.

Design: Semi-structured interviews ( $n$ 18) were conducted with key informants from various sectors. Interviewees were asked about sources of trans fat in the food supply, existing policies that may influence trans fats and perceived challenges related to the proposed trans fat regulation, in addition to questions tailored to their area of expertise. Interview data were organised based on common themes.

Setting: Interviews were conducted in India.

Subjects: Interviewees were key informants from various sectors including agriculture, trade, industry and health.

Results: Several themes were identified related to the complexity of regulating trans fat in India. A lack of trans fat awareness, the large unorganised retail sector, a need for suitable alternative products that are both acceptable to consumers and affordable, and a need to build capacity were crucial factors affecting India's ability to successfully regulate trans fat. The limited number of food inspectors will create an additional challenge in terms of enforcement of trans fat regulation.

Conclusions: Although India will face challenges in regulating trans fat, legislating an upper limit of trans fat in partially hydrogenated vegetable oils will likely be the most effective approach to reducing it in the food supply. Ongoing engagement with industry, agriculture, trade and processing sectors will prove essential in terms of product reformulation.
\end{abstract}

Consumption of industrially produced trans-fatty acids (trans fat) increases the risk of cardiovascular and other non-communicable diseases $(\mathrm{NCD})^{(1-3)}$. The WHO recommends that trans fat intakes should be limited to less than $1 \%$ of total energy intake and has called for the elimination of trans fats from the global food supply ${ }^{(4,5)}$. Consumption of trans fat is high in many populations, including low- and middle-income countries where the use of partially hydrogenated vegetable oils (PHVO) is $\operatorname{high}^{(2,6-8)}$.

In order to effectively reduce intakes of trans fat some high-income countries have mandated trans fat labelling, promoted public education campaigns and legislated an upper limit of trans fat in food products ${ }^{(9)}$. Most notably,
Denmark became the first nation to set an upper limit of trans fat in 2003 and within less than a year trans fats were essentially removed from the food supply ${ }^{(10-12)}$. The Government of India is now proposing to regulate trans fat. In India, the main source of trans fat is vanaspati, a form of vegetable ghee that is a PHVO. Vanaspati is used mainly in street vendor foods and bakery products; however, it is also used as a cooking oil in the northern Indian states ${ }^{(6,13,14)}$. Although the quantity of trans fat present in vanaspati depends on the brand, a Food Safety and Standards Authority of India (FSSAI) report suggests that levels could be as high as $50-60 \%$ of total fat content ${ }^{(15)}$. In response to the high levels of trans fat in PHVO such as vanaspati, in 2004 the Oils and Fats sub-Committee 
of the Central Council for Food Standards (now the FSSAI) suggested the need for trans fat regulation in PHVO. In November 2009, the FSSAI proposed a regulation that includes an upper limit of $10 \%$ trans fat in PHVO such as vanaspati, to be further reduced to $5 \%$ over three years. In addition, the regulation would include mandatory labelling of both saturated and trans fat. Although there have been many discussions and deliberations about regulating trans fat in India, the regulation has yet to be passed by the central government.

Denmark and New York City have successfully reduced trans fat in their food supplies with mandatory regulation $^{(12,16,17)}$. However, it has been suggested that low- and middle-income countries may face additional challenges ${ }^{(1)}$, complicated by the high consumption of $\mathrm{PHVO}^{(7,8)}$. Key factors that have led to the success of trans fat regulation in high-income countries have been high consumer and political awareness regarding the health implications of trans fat consumption and champions in consumer organisations $^{(9)}$.

The present study is part of a larger project examining trans fat policy in India using a food systems approach. This approach provides a detailed picture of the way the food system works, from one step of the food supply chain to the next. The overarching goal of the project is to understand the existing policies that affect the availability of trans fat in the Indian food supply, in order to enable the identification of pressure points in the supply chain where changes could be made to help facilitate trans fat reduction. The objective of the present study was to examine the complexities of regulating (both limiting and labelling) trans fat in India by examining the policy processes involved and the perceived implementation challenges.

\section{Methods}

\section{Setting}

Data collection was conducted in India between February and October 2011. Interviews were conducted to gain a thorough understanding of the policy process and perceived implementation challenges. The majority of interviews were conducted at the national level; however, three were completed at the state level. Ethics approval for the study was obtained from the University of Sydney Human Research Ethics Review Committee and from the Institutional Ethics Committee at the Public Health Foundation of India.

\section{Study design and participants}

Eighteen semi-structured interviews were conducted with key informants from agriculture, trade, finance, industry, food standards and non-governmental organisations (NGOs), including one organisation representing the unorganised retail sector, as well as health professionals (including nutritionists). Five interviews were conducted with informants from the health sector (including food standards) and the remainder were completed with participants from sectors outside health. Initial interviewees in government, public organisations and the private sector were identified by policy documents and co-researchers in India. Additional informants were recruited using snowball sampling, a chain of referral to identify potential informants ${ }^{(18)}$. Interviewees were selected based on their roles as key decision makers in their related sectors. The majority of key informants were presidents/directors of their companies, organisations or government departments and were actively involved in the policy decision making, implementation or enforcement process. Specific sectors were selected based on their role in each step of the food supply chain. Interviews continued until informants from each step of the food supply chain had been interviewed and to the point where theoretical saturation appeared to have been reached, i.e. when no additional relevant information was coming from interviews ${ }^{(19,20)}$. However, it is difficult to be certain that true theoretical saturation was achieved because of the small number of interviews ${ }^{(20)}$.

Introductory emails were sent to potential participants explaining the study prior to contacting them by telephone to seek their participation. Written informed consent was obtained from all study participants. Interviews were conducted mainly face-to-face; however, three were completed by telephone. Interviews were audio-recorded, when permitted by the interviewee, and transcribed verbatim. Detailed notes were taken for interviewees ( $n$ 4) who did not consent to being audiorecorded. The same interviewer, usually accompanied by a local co-researcher, conducted all of the interviews. Interviews took an average of $45 \mathrm{~min}$ to complete.

The semi-structured interviews used predetermined topics, tailored to the interviewees' areas of expertise ${ }^{(21)}$. All interviewees were asked about sources of trans fat in the food supply, existing policies that may influence trans fat and about any perceived challenges related to the proposed trans fat regulation, in addition to the interview questions specifically designed for their area of expertise. The responses from these questions led to an abundance of information related to the complexity of regulating trans fat in India, which is reported below. The interview process was iterative, with the interviewer following up on points of interest and responses from one interview informing the next ${ }^{(22,23)}$. One of the advantages of using semi-structured interviews was that the interviewer had the flexibility to modify questions or to follow up on a point of interest ${ }^{(23)}$.

\section{Analysis}

Interview data were analysed using NVivo software version 8. An amalgamation of two analytical policy frameworks was used to organise the interview data. 
The first framework, developed by Walt and Gilson ${ }^{(24)}$, examines the policy context, content, process and actors. Additional constructs from the framework developed by Najam ${ }^{(25)}$, namely commitment and capacity, were also used to establish a descriptive framework for the thematic analysis. These frameworks have been used to study the policy process, including trans fat policy, in low- and middle-income countries ${ }^{(9,26)}$. It has been suggested that health policy analysis, especially of highly complex environments, should be approached in a systematic way within explicit analytical frameworks ${ }^{(27)}$. The framework used in the present study was chosen to enable a detailed analysis of the different constructs of the policy process, as well as their interaction with each other. Figure 1 depicts the framework and Table 1 describes each of the framework constructs. Interview data were initially open-coded, combined into key themes and subsequently organised based on the analytical framework; all data were coded by the primary interviewer. Although the policy process framework was used to conduct data analysis, the results are presented based on key themes.

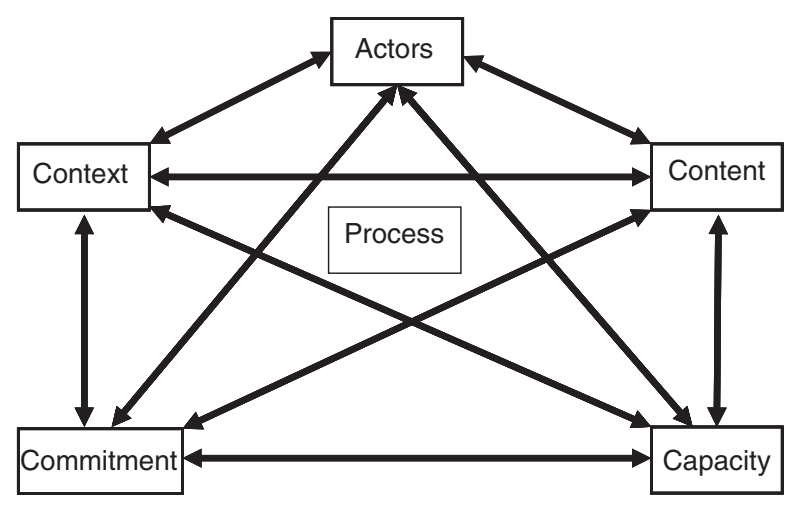

Fig. 1 Analytical framework for thematic analysis based on the policy constructs from Walt and Gilson ${ }^{(24)}$ and Najam ${ }^{(25)}$

Table 1 Description of constructs from the analytical framework $^{(24,25)}$

\begin{tabular}{|c|c|}
\hline Construct & Description of construct \\
\hline Content & The content of the policy \\
\hline \multirow[t]{2}{*}{ Context } & $\begin{array}{l}\text { Contextual factors which can have an impact on } \\
\text { policy }\end{array}$ \\
\hline & $\begin{array}{l}\text { - Situational: the transient or impermanent } \\
\text { conditions } \\
\text { - Structural: the relatively unchanging elements } \\
\text { - Cultural: the cultural factors } \\
\text { - International: the international or exogenous } \\
\text { factors }\end{array}$ \\
\hline Actors & $\begin{array}{l}\text { The individuals, groups and organisations who } \\
\text { interact and influence policy }\end{array}$ \\
\hline Process & $\begin{array}{l}\text { The way in which policies are initiated, } \\
\text { developed/formulated, negotiated, } \\
\text { communicated, implemented and evaluated }\end{array}$ \\
\hline Commitment & $\begin{array}{l}\text { The commitment of those entrusted with } \\
\text { carrying out the policy process }\end{array}$ \\
\hline Capacity & $\begin{array}{l}\text { The administrative ability of implementers to } \\
\text { carry out the policy implementation }\end{array}$ \\
\hline
\end{tabular}

\section{Results}

\section{Trans fat awareness}

A key situational (impermanent or transient) contextual factor relating to the complexity of regulating trans fat in India was a lack of trans fat awareness by both consumers and street vendors. As one interviewee stated:

The food safety [and standards] authority also needs to create awareness, you know, because you can't just make rules and expect people somewhere in some part of India to know what trans fat is.

Although some interviewees noted a 'colloquial' understanding that vanaspati was unhealthy, this was not attributed to trans fat. Moreover, interviewees indicated that people were likely unaware of the presence of vanaspati in many foods since it is largely consumed through indirect sources, i.e. in baked goods, sweet meats (Indian sweets) and deep-fried street foods. An important theme that was highlighted by several informants was the perceived lack of practicality of the proposed labelling regulations, given the lack of trans fat awareness.

Many interviewees were concerned that because such a large proportion of foods high in trans fat are sold in the loose market, without labels, mandating trans fat labelling would have little effect on intakes. In terms of the actual use of food labels, an interviewee from an NGO indicated that the public does not pay attention to nutrition labels, with the exception of expiry dates:

...they don't bother about the nutritional information. That is the area we have to create awareness.

There was a general consensus that street vendors lacked trans fat awareness. The use and re-use of oil by street vendors resulting in 'abused' oil may also contribute to increased trans fat levels in street foods and jeopardise food safety. As one health professional noted:

[The] halwais [street vendors], they probably keep the oil heated for almost 12 hours and they re-use the oil also. So vanaspati is extremely stable as compared to unsaturated fats. It's more stable for multiple re-use. So 12 hours heating on a couple of days' basis it causes an abused oil and a higher proportion of trans fats.

\section{Identification of trans fat as a problem}

Many of the interviewees highlighted the apparent commitment of the government in identifying trans fat as a problem, noting however, the number of food safety issues that must be dealt with by the FSSAI (i.e. food adulteration) which may lead to other food safety issues being given priority over trans fat regulation. Although the majority of the interviewees acknowledged trans fat as a public health issue, there were some industry informants who described the problem as exaggerated. 
In addition, the ongoing problem of undernutrition was seen as a more pressing health issue. In relation to the discourse on trans fat one interviewee said:

Just mentioning trans fat in a global setting is like setting off a bomb. It's evil, bad; it's Satan in a new guise. It's extreme.

Moreover, some industry informants attributed the rise in NCD to smoking and physical inactivity rather than unhealthy diets.

\section{Large unorganised retail sector}

The large unorganised retail sector, which caters to the needs of the poor, was one of the main structural (the relatively unchanging elements) contextual factors relating to the complexity of regulating trans fat in India. Interviewees noted that the large unorganised retail sector will affect the feasibility of implementing the proposed trans fat regulation given that the main sources of trans fat were not the packaged, branded foods but rather the foods found in the 'loose' unregulated market available at cheaper prices. Informants indicated that in villages, people might simply purchase a 'scoop' of vanaspati at a time, not bothering about its brand. Importantly, although the retail sector is largely informal, all manufacturers of vanaspati have to be formally registered.

\section{Support for proposed trans fat regulation}

Overall, interviewees appeared to support the proposed trans fat regulation. As one industry informant stated:

We really appreciate the government taking [a] positive direction... So today ... we are in the phase of transition and once we have completed that entire journey and we have kind of settled down with regulation and legislation we should have a much better scenario than what we have today... I think the government and these authorities are conscious and mindful of the challenges that they have. One of these is how will we really make sure that the food safety is achieved for a very large unregulated food market.

Although some industry informants showed commitment to reducing trans fat in their products, there was discrepancy in terms of their intentions. For example, as one interviewee noted:

Industry here in India - we are all committed to bring down the trans [fat] and produce healthier products for the consumer, because that is the need of the hour.

However, another industry informant stated:

More studies need to be conducted on consumption patterns, and food baskets. The removal of trans fat is more the NGOs that are pushing for something.
We, as industry, are very unhappy with it [the regulation].

Moreover, multiple industry informants suggested that there was a possibility of the proposed regulation becoming voluntary self-regulation rather than mandatory. A few informants noted the need for global trans fat standards that would increase buy-in for regulation in their own country.

\section{Multisectoral engagement}

Interviewees from health organisations, government, NGO and industry all acknowledged the importance of including industry in the trans fat policy discussions. As one health professional stated:

We have to involve industries in this regard ... until and unless you sensitise the food industries for a limitation of trans fat it cannot work ... so that's why still negotiations are going on.

Furthermore, a government informant said:

Whatever regulation we bring, they [industry] should be part of it; also, they should be reasonable.

However, excluding engagement with industry, many interviewees acknowledged that cross-sector coordination was often lacking. In particular, there was limited involvement of the agriculture sector in the policy process. As one interviewee from agriculture noted:

Nutrition is a very broad subject ... about 13 ministries are involved in it ... the coordination is not much because everybody is working independently.

An interviewee from trade reiterated this point:

The biggest problem in India is it's not very synergised; their policies are not very synergised even within the department of the same ministry.

NGO were involved in advocacy relating to trans fat regulation but strong leadership was not apparent.

\section{Suitability of product reformulation}

Industry informants noted that 'there are challenges but industry is getting geared up' to produce healthier alternative products to vanaspati; however, this will take time and investment in new technology since finding a suitable alternative with similar organoleptic (i.e. sensory) properties to vanaspati may be difficult. Cultural factors that interviewees noted would influence the acceptability of products were consumer preferences (including the desirable texture of vanaspati) and price consciousness. For example, one industry informant said:

One has to check the functional performance of the product, the shelf life, the dipping quality, so all those factors are going to be there. 
This will be even more difficult given the price consciousness of the Indian consumer:

If you have to create a good and nutritious food safe biscuit which you can sell, say 15 pieces of those big biscuits, for let's say 5 rupees or 7 rupees, you have to be conscious of your input costs. You can't say that I am going to make a biscuit out of olive oil and sell it at 5 rupees. It's not possible.

Interviewees acknowledged the lack of evidence for some existing policies, which will affect their ability to reformulate products in an acceptable way. One of the complaints by industry informants was the lack of evidence to support the provisions on capping the melting point, excluding palm stearin as an edible oil and restricting blending to only two oils when producing vanaspati:

I mean why do we want to bring the trans down? Because we understand that there is an inherent risk with a higher trans fat intake in the body. So there's a scientific reason why we would. Similarly if you want to have legislation on say slip melting point or not allowing the palm stearin or the hard fraction of palm into your category you have to understand that there has to be logic behind it. The logic cannot be a lame excuse.

\section{Implementation and enforcement capacity}

All interviewees mentioned the importance of recognising the heterogeneity of India, leading to difficulties in policy implementation. As one interviewee stated:

You really can't just take a western regulation, and then decide to plunk it on India. You can't take the regulation from one country in the world and use it on a country like India.

There were several key themes related to the policy implementation and enforcement. As one interviewee from an NGO stated:

We have to have practical regulations, which are feasible, which can be done. The people who are making regulations are not people on the street. People who are sitting in cosy offices, they are not aware of the reality. That is why there is a gap in the country between law and its implementation.

Lack of resources (both human and financial) for enforcement and reported unethical practices by some inspectors were key themes related to enforcement capacity in India. Capacity building was seen as an important component of increasing the feasibility of the proposed regulation from interviewees from all sectors. The paucity of inspectors and laboratories to test samples, coupled with perceived vendor distrust of some inspectors, will create a challenge for enforcement.
Several interviewees noted the unethical practices of food inspectors in response to efforts to dissuade them from imposing fines on street vendors. Concerning the significant lack of resources for enforcement, an interviewee from an NGO said:

Even if you go to each and every vendor probably in a whole month you won't be able to visit all of them.

In an effort to try to overcome these challenges, government informants noted the need for 'shared responsibility':

Earlier we were trying to enforce things. Now we realised, it is not the responsibility of the [food standards and safety] authority only, it is everybody's responsibility. It is a shared responsibility. So, it should be the responsibility of ... the [food] business operator. They should be involved and the whole enforcement should be participatory.

\section{Discussion}

Removing trans fat from the food supply has been deemed one of the most straightforward public health strategies to improve diets and reduce NCD ${ }^{(28)}$. There is evidence from countries such as Denmark that through legislation trans fat can be completely removed from the food supply ${ }^{(12)}$. Although Denmark made the process of eliminating trans fat look relatively easy, India will experience additional challenges for its removal. We found a lack of consumer and vendor awareness, a large unorganised retail sector, a need for suitable alternative products that are both acceptable to consumers and affordable, as well as a need to build capacity for implementation and enforcement as crucial factors that will affect India's ability to successfully regulate trans fat.

\section{'The common man, I don't think be really understands the concept of trans fats ...'}

High consumer awareness concerning the health implications of trans fat was a key factor leading to the success of trans fat regulation in high-income countries $^{(9)}$. In India, the lack of consumer awareness will affect the type of regulation that has the potential to succeed in the country. Studies in Mexico and Costa Rica have also found lack of awareness to be a barrier to regulating trans fat $^{(9,26)}$. In the USA, Canada and other countries worldwide, consumers were aware of trans fat ${ }^{(29)}$. Because of this, people demanded products that were low in trans fat, leading to product reformulation by industry. This was facilitated through mandatory labelling of trans fat on packaged foods and has led to significant reductions in trans fat intakes ${ }^{(30)}$.

In contrast, Denmark deemed trans fat labelling to be insufficient to reach the appropriate level of population 
protection, so the government legislated an upper limit of trans fat in spreads and food items - cutting trans fat at the source ${ }^{(12)}$. It is likely that legislating an upper limit of trans fat in PHVO will be the most feasible way to reduce trans fat intakes in India, given its large unorganised retail sector of loose unpackaged food that caters to the food needs of the common man. In high-income countries, large proportions of food containing trans fat are packaged and can thus be easily labelled; the Indian context is markedly different. Many Indians purchase foods laden with trans fat in the loose market in an unpackaged form, although the recently rolled out Food Safety and Standards $\mathrm{Act}^{(31)}$ prohibits this. The loose market will limit the effectiveness of trans fat labelling ${ }^{(8)}$, since people will continue to purchase foods without labels. Because structural contextual factors such as the large unorganised retail sector will be difficult to change, policy changes aimed at removing trans fat at the point of manufacture are important.

Champions in government and consumer organisations have facilitated trans fat regulation in high-income countries $^{(9)}$. In Denmark, the work of the Danish Nutrition Council and the media attention it gained proved instrumental in winning consumer buy-in for trans fat legislation $^{(11)}$. In New York City, Mayor Bloomberg championed trans fat regulation in restaurant food ${ }^{(32)}$. Although there has been advocacy for the regulation of trans fat in India, strong and persistent leadership has not yet been seen. The lack of policy maker attention and advocacy by health professionals could be attributed to their concern with the high prevalence of undernutrition. Traditionally, the view of nutrition experts in India has been that any fat is good because it provides much needed energy, with much less emphasis being given to the quality of the fat. However, if NGO/consumer organisations and other advocates were to mobilise, they might positively influence some of the situational contextual factors, such as increasing consumer awareness of trans fat, which could generate greater demand for the removal of trans fat from the food supply.

\section{'They [industry] should be part of it: also they should be reasonable'}

Engagement with industry was seen as being an important part of the trans fat policy process. Although some stakeholders show unease while engaging with industry, it is often necessary since they are the ones producing the end product ${ }^{(33)}$. However, there is a concern that industry may interfere with public health goals, particularly when governments are considering regulation ${ }^{(33)}$. Industry preference for voluntary rather than mandatory regulation in India reflects the global experience. Although voluntary initiatives by industry have succeeded in countries including the Netherlands, where industry took a proactive approach to removing trans fat from foods ${ }^{(34)}$, the immensity and complexity of India make this an unlikely outcome there. In New York City, voluntary compliance was first proposed to reduce trans fat levels in restaurant foods but failed, necessitating mandatory limits ${ }^{(35)}$. In Canada, a voluntary approach was taken to limiting trans fat, but trans fat is still present in foods ${ }^{(36-38)}$. In fact, the government has recently received criticism for not mandating regulation after many industry players failed to comply with the voluntary guidelines.

\section{'More studies need to be conducted'}

Interestingly, industry in India had disparate views regarding the identification of trans fat as a public health problem. Although some interviewees appeared genuinely concerned about the problem and were committed to reformulating their products, others questioned whether there was sufficient evidence for the removal of trans fat from the food supply. This is a common tactic used by industry to ward off public health regulation. In Denmark, one of the reasons for the relative ease of regulating trans fat was that there was little resistance from industry ${ }^{(11,12)}$. Similarly, in the Netherlands, industry reformulated products and switched oils without government interference, something that was noted as uniquely Dutch ${ }^{(34)}$. In India, having mandatory regulation will provide a level playing field for industry and ensure that all industries comply regardless of their views relating to the evidence.

\section{'There are challenges but industry is getting geared up'}

Although the majority of industry members showed support for the proposed trans fat regulation, product reformulation is neither easy nor cheap. The three main challenges include the identification and availability of suitable oils, the cost of substitution and concern about consumers' acceptance of reformulated products ${ }^{(39)}$. In most cases industry has been able to make acceptable products without trans fat ${ }^{(40)}$. However, it is difficult to reformulate products such as vanaspati that are used in bakery products while retaining their organoleptic properties $^{(41)}$.

The problems in achieving trans fat reductions in India are not unique. Vanaspati is consumed not only in India, but also in other countries in Asia and the Middle East that are experiencing high rates of diet-related $\mathrm{NCD}^{(7,42)}$. Product reformulation offers a way to ensure optimal fatty acid composition in the diets of many populations in lowand middle-income countries. Increasing the availability of cost-effective alternatives to products high in trans fat will require extensive engagement with industry ${ }^{(43)}$. In both Argentina and Costa Rica, strong linkages between industry and oil producers led to greater availability of suitable alternative oils ${ }^{(26,44)}$. There has been little engagement with the agriculture and trade sectors in regulating trans fat in India. Palm oil, because of the availability and price, may be substituted for PHVO in some products but it is high in saturated fat. The removal 
of trans fat has the most health benefits when replaced with polyunsaturated and monounsaturated fats rather than saturated fats ${ }^{(3)}$. There is an insufficient supply of appropriate polyunsaturated and monounsaturated fats to meet the demand of PHVO replacement ${ }^{(4,45)}$, but if demand for these alternative oils continues to increase, the global supply and quality will improve ${ }^{(28)}$. For this reason, it is important that industry engages with agriculture and trade to identify and produce/import healthier alternative oils that will not lead to marked rises in price. The current lack of coordination among sectors is problematic given that concern with nutrition crosses multiple sectors and government ministries. Establishing a coherent national nutrition policy in India that aligns different sectors to meet the nutritional needs of the country could have a significant impact on health.

\section{'There is a gap in the country between law and its implementation'}

Building capacity for manufacturers and vendors will be imperative as India moves forward with trans fat regulation. In both New York City and California, the health department assisted the restaurant industry in identifying cost-effective strategies to remove trans fat from its products ${ }^{(35,46)}$. Building capacity for Indian industry through increasing the availability of suitable alternative oils and finding technological solutions for product reformulation will be important, particularly for smaller, independent companies. Although the FSSAI does not plan to assist industry in this process, the Directorate of Vanaspati, Vegetable Oils and Fats has given small grants to companies for research and development into the reduction of trans fat from their products. Providing incentives for the adoption of technology to reformulate products with minimal increases in saturated fat could result in significant health benefits.

Perhaps one of the most significant challenges that India will face in trans fat regulation will be enforcement. It has previously been suggested that there is a need for a regulatory framework that can effectively enforce trans fat levels in India ${ }^{(6)}$. Currently, there is one sole food inspector per district in India. Moreover, several interviewees noted the perceived unethical practices of some inspectors in order for street vendors to elude fines. Although the government foresees a shared responsibility for enforcement, this will only come with increasing capacity of both street vendors and inspectors. Given the limited budget for enforcement, this reinforces the need to remove trans fat at the source, the manufacturer level, which may prove to be more feasible.

\section{Conclusions}

Regulating (both limiting and labelling) trans fat in India is confounded by lack of consumer and vendor awareness, an unorganised retail sector, unique product reformulation needs and the lack of capacity ranging from production of alternative oils through to inspection and enforcement of restrictive laws. However, government has shown commitment, as have parts of industry. Ongoing engagement with industry to facilitate product reformulation is necessary and will likely be viewed favourably, given its acceptance by non-industry actors. Incentives for industry to invest in technology to develop products that are cost-effective and acceptable to consumers and to limit increases in saturated fat levels will be important. Liaising with the agriculture, trade and processing sectors in a cohesive way will prove essential to moving forward with healthier replacement oils. It is unlikely that mandating trans fat labelling will be an effective means of reducing trans fat intakes in India. Removing trans fat at the point of manufacture has the most potential in terms of reducing its presence in the food supply and managing enforcement in a country with limited inspectorial capacity.

\section{Acknowledgements}

Sources of funding: The study received no specific grant from any funding agency in the public, commercial or not-for-profit sector. S.M.D. received funding from the Canadian Institutes of Health Research Doctoral Research Award and the Commonwealth Government International Postgraduate Award. Conflicts of interest: The authors report no conflicts of interest. Authors' contributions: S.M.D. was involved in all aspects of the study. A.M.T. was involved in the study design, analysis and manuscript preparation. S.G.-J. was involved in data collection and manuscript preparation. J.M. was involved in data analysis and manuscript preparation. K.S.R. and S.R.L. were involved in both study design and manuscript preparation.

\section{References}

1. Micha R \& Mozaffarian D (2008) Trans fatty acids: effects on cardiometabolic health and implications for policy. Prostaglandins Leukot Essent Fatty Acids 79, 147-152.

2. Teegala SM, Willett WC \& Mozaffarian D (2009) Consumption and health effects of trans fatty acids: a review. JAOAC Int 92, 1250-1257.

3. Mozaffarian D \& Clarke R (2009) Quantitative effects on cardiovascular risk factors and coronary heart disease risk of replacing partially hydrogenated vegetable oils with other fats and oils. Eur J Clin Nutr 63, Suppl. 2, S22-S33.

4. Uauy R, Aro A, Clarke R et al. (2009) WHO Scientific update on trans fatty acids: summary and conclusions. Eur J Clin Nutr 63, Suppl. 2, S68-S75.

5. World Health Organization (2004) Global Strategy on Diet, Physical Activity and Health. http://www.who.int/ dietphysicalactivity/strategy/eb11344/en/index.html (accessed January 2012). 
6. Ghafoorunissa G (2008) Role of trans fatty acids in health and challenges to their reduction in Indian foods. Asia Pac J Clin Nutr 17, 212-215.

7. Butt MS \& Sultan MT (2009) Levels of trans fats in diets consumed in developing economies. J AOAC Int 92, 1277-1283.

8. Agrawal A, Gupta R, Varma K et al. (2008) High trans fatty acid content in common Indian fast foods. Nutr Food Sci 38, 564-569.

9. Perez-Ferrer C, Lock K \& Rivera JA (2010) Learning from international policies on trans fatty acids to reduce cardiovascular disease in low- and middle-income countries, using Mexico as a case study. Health Policy Plan 25, 39-49.

10. Bysted A, Mikkelsen AA \& Leth T (2009) Substitution of trans fatty acids in foods on the Danish market. Eur J Lipid Sci Technol 111, 574-583.

11. Astrup A (2006) The trans fatty acid story in Denmark. Atheroscler Suppl 7, 43-46.

12. Leth T, Jensen HG, Mikkelsen AAE et al. (2006) The effect of the regulation on trans fatty acid content in Danish food. Atheroscler Suppl 7, 53-56.

13. Coombes R (2011) Trans fats: chasing a global ban. BMJ 343, d5567.

14. L'Abbé MR, Stender S, Skeaff M et al. (2009) Approaches to removing trans fats from the food supply in industrialized and developing countries. Eur J Clin Nutr 63, Suppl. 2, S50-S67.

15. Food Safety and Standard Authority of India (2010) Regulation of trans fatty acids in partially hydrogenated vegetable oils. http://www.fssai.gov.in/Portals/0/Regulation_ of_TFA_.pdf (accessed January 2011).

16. Angell SY, Silver LD, Goldstein GP et al. (2009) Cholesterol control beyond the clinic: New York City's trans fat restriction. Ann Intern Med 15, 129-134.

17. Angell SY, Cobb LK, Curtis CJ et al. (2012) Change in trans fatty acid content of fast-food purchases associated with New York City's Restaurant Regulation: a pre-post study. Ann Intern Med 157, 81-86.

18. Bell E (2010) Research For Health Policy. New York: Oxford University Press.

19. Bertaux D (editor) (1981) From the life-history approach to the transformation of sociological practice. In Biography and Society: The Life History Approach in the Social Sciences, p. 37. Beverly Hills, CA: SAGE Publications.

20. Quine S (1998) Sampling in non-numerical research. In Handbook of Public Health Methods, pp. 539-542 [C Kerr, R Tayor and G Heard, editors]. Sydney: McGraw-Hill.

21. Yin RK (2009) Case Study Research: Design and Methods, 4th ed. Thousand Oaks, CA: SAGE Publications.

22. Grbich C (1999) Qualitative Research in Health. Sydney: Allen \& Unwin.

23. Robson C (2002) Real World Research. Malden: Blackwell Publishing.

24. Walt G \& Gilson L (1994) Reforming the health sector in developing-countries - the central role of policy analysis. Health Policy Plan 9, 353-370.

25. Najam A (1995) Learning from the literature on policy implementation: a synthesis perspective. http://www. iiasa.ac.at/Admin/PUB/Documents/WP-95-061.pdf (accessed August 2011).

26. Colon-Ramos U, Lindsay AC, Monge-Rojas R et al. (2007) Translating research into action: a case study on trans fatty acid research and nutrition policy in Costa Rica. Health Policy Plan 22, 363-374.
27. Walt G, Shiffman J, Schneider H et al. (2008) 'Doing' health policy analysis: methodological and conceptual reflections and challenges. Health Policy Plan 23, 308-317.

28. Mozaffarian D (2010) Removing industrial trans fat from foods. BMJ 340, 1094-1095.

29. Eckel RH, Kris-Etherton P, Lichtenstein AH et al. (2009) Americans' awareness, knowledge, and behaviors regarding fats: 2006-2007. J Am Diet Assoc 109, 288-296.

30. Vesper H, Kuiper H, Mirel L et al. (2012) Levels of plasma trans-fatty acids in non-Hispanic White adults in the United States in 2000 and 2009. JAMA 307, 562-563.

31. Food Safety and Standards Authority of India (2011) Food Safety and Standards Rules. http://www.fssai.gov.in/ AboutFSSAI/FSSAct.aspx (accessed March 2012).

32. McColl K (2008) New York's road to health. BMJ337, a673.

33. Hawkes C \& Buse K (2011) Public-private engagement for diet and health: addressing the governance gap. SCN News issue 39, 6-10.

34. Katan MB (2006) Regulation of trans fats: the gap, the Polder, and McDonald's French fries. Atheroscler Suppl 7, 63-66.

35. Mello M (2009) New York City's war on fat. N Engl J Med 360, 2015-2020.

36. Vogel L (2010) Public health and nutrition advocates fear regulatory inaction has become the norm. CMAJ 182, E465-E466.

37. Ricciuto L, Lin K \& Tarasuk V (2009) A comparison of the fat composition and prices of margarines between 2002 and 2006, when new Canadian labelling regulations came into effect. Public Health Nutr 12, 1270-1275.

38. Ratnayake WMN, L'Abbe MR, Farnworth S et al. (2009) Trans fatty acids: current contents in Canadian foods and estimated intake levels for the Canadian population. J AOAC Int 92, 1258-1276.

39. Monge-Rojas R, Colon-Ramos U, Jacoby E et al. (2011) Voluntary reduction of trans-fatty acids in Latin America and the Caribbean: current situation. Rev Panam Salud Publica 29, 126-129.

40. Nielsen K (2006) Is the quality and cost of food affected if industrially produced trans fatty acids are removed? Atheroscler Suppl 7, 61-62.

41. Tarrago-Trani MT, Phillips KM, Lemar LE et al. (2006) New and existing oils and fats used in products with reduced trans-fatty acid content. J Am Diet Assoc 106, $867-880$

42. Farmani J, Safari M \& Hamedi M (2006) Application of palm olein in the production of zero-trans Iranian vanaspati through enzymatic interesterification. Eur J Lipid Sci Technol 108, 636-643.

43. Skeaff CM (2009) Feasibility of recommending certain replacement or alternative fats. Eur J Clin Nutr 63, Suppl. 2, S34-S49.

44. Pan American Health Association (2008) Healthy Oils and the Elimination of Industrially Produced Trans Fatty Acids in the Americas: Initiative for the Prevention and Control of Chronic Diseases. http://www.healthycaribbean.org/ publications/trans_fatty_acids.html (accessed January 2012).

45. Gerberding JL (2009) Safer fats for healthier hearts: the case for eliminating dietary artificial trans fat intake. Ann Intern Med 21, 137-138.

46. Redelings MD, Piron J, Smith LV et al. (2010) Readiness and perceived barriers to removing artificial trans-fat from restaurant menus. J Public Health Policy 31, 119-127. 